\title{
Adverse reactions to foods
}

\author{
BY A. E. BENDER AND DIANA R. MATTHEWS \\ Department of Nutrition, Queen Elizabeth College, London W8 7 AH
}

(Re'ceived 5 March 1981-Accepted 20 July 1981)

\begin{abstract}
1. One thousand individuals were asked whether they avoided any foods. Of the 560 replies $33 \%$ stated that they avoided one or more foids because they caused 'unpleasant physiological reactions'.

2. Adverse reactions to one of thirteen foods were reported by $1-4 \%$ of the respondents and it is suggested that this number might be regarded as a standard with which to compare reactions to novel foodstuffs. A total of sixty-seven foods were specifically mentioned as a cause of an adverse reaction.
\end{abstract}

Many people suffer reactions to foods including chemical intolerance, chemical idiosyncrasies, intoxication by known poisons and allergies. Reactions to food are often grouped together under the tern allergies, but they can be classed as such only when there is a specific immunological response (Lancet, 1979; Wilson, 1979). Some workers have defined allergy as a skin reaction or heavy vomiting after ingestion of the food (Saarinen \& Kajosaari, 1980) but this definition has been criticized (Soothill, 1980).

When dealing with individual patients it is possible to ascertain whether the effect is a true allergy (Vaz et al. 1978; Monro et al. 1980) but such numbers are necessarily small and it is not possible tio ascertain the frequency of allergic response to foods among the general public. The problem has become of increasing importance with the introduction of novel foods derived. from micro-organisms and of foods new to the community in question. The first step is to ascertain the numbers who have adverse reactions to ordinary accepted foods and so possibly provide a standard for novel products.

\section{METHODS}

One thousand questionnaires were posted to members of the teaching staff of London University ( 500 males, 500 females) selected at random from 6300 males and 900 females. In an attempt to avoid self-selection by respondents who suffer adverse reactions to foods the purpose of the questionnaire was disguised by the inclusion of (irrelevant) questions about shopping and eating habits.

Subjects were asked if they avoided any particular food or drink and reasons for such avoidance. These reasons were listed on the questionnaire as religion, taste, texture, headache-migraine, vomiting, nausea, skin reaction and 'other'. Subjects volunteered diarrhoea, indigestion and tremor under 'other'. They were also asked how long after eating the food such reactions occurred.

\section{RESULTS}

Of the 1000 persons questioned 560 returned useable replies in the ratio 48 males: 52 females. $33 \%(26 \%$ of the males and $39 \%$ of the females) stated that they avoided specific foods because they experienced unpleasant physiological reactions after consuming them. Of the respondents $25 \%$ avoided a food for a variety of other reasons as shown in Table 1 . Only religion, taste and texture were listed on the questionnaire as non-physiological reasons for food avoidance, the subjects themselves volunteered weight, health, medical and ethicalmoral. Reasons descrited as preventive measures against coronary heart disease and dental health were grouped under 'health'. 'Medical' represents foods that subjects had been 
Table 1. Reasons for food avoidance

\begin{tabular}{|c|c|c|c|c|c|c|c|c|}
\hline \multirow[b]{2}{*}{ Food group } & \multicolumn{8}{|c|}{ Reason for food avoidance } \\
\hline & Religion & Taste & Texture & Weight & Health & Medical & $\begin{array}{l}\text { Ethical } \\
\text { - moral }\end{array}$ & $\begin{array}{l}\text { Adverse } \\
\text { reaction }\end{array}$ \\
\hline Cereals and cereal products & - & 27 & 19 & 67 & 18 & 3 & - & 19 \\
\hline Milk and milk products & - & 29 & 17 & 34 & 9 & 10 & 2 & 40 \\
\hline Eggs & - & 2 & 1 & 1 & 2 & 1 & 2 & 5 \\
\hline Fats and oils & - & 7 & 3 & 30 & 10 & 3 & 1 & 10 \\
\hline Offal & - & 42 & 23 & - & - & 1 & - & - \\
\hline Meat and meat products & 14 & 19 & 14 & 5 & 9 & 3 & 10 & 29 \\
\hline Fish and fish products & 7 & 17 & 14 & - & 1 & - & 2 & 23 \\
\hline Vegetables & - & 47 & 10 & 19 & - & 3 & 1 & 30 \\
\hline Fruit & - & 13 & 4 & - & 1 & 5 & 2 & 10 \\
\hline Sugars and sugar confectionery & - & 23 & 6 & 64 & 22 & 3 & 1 & 22 \\
\hline Alcoholic beverages & 2 & 11 & 4 & - & 4 & 2 & 1 & 36 \\
\hline Miscellaneous & - & 14 & 1 & 2 & 7 & 4 & 3 & - \\
\hline Beverages & - & 13 & 2 & - & - & 5 & - & - \\
\hline Total & 23 & 263 & 119 & 222 & 83 & 45 & 25 & 224 \\
\hline
\end{tabular}

Table 2. Types of physiological effect (total 560 replies)

\begin{tabular}{|c|c|c|c|c|c|c|}
\hline \multirow[b]{2}{*}{ Effect } & \multicolumn{3}{|c|}{ Percentage of total } & \multicolumn{3}{|c|}{$\begin{array}{c}\text { Percentage of subjects } \\
\text { who suffer } \\
\text { physiological effect }\end{array}$} \\
\hline & $\sigma^{3}$ & $q$ & Combined & $\hat{0}$ & $q$ & Combined \\
\hline Headache-migraine* & 3 & 6 & 5 & 11 & 15 & 14 \\
\hline Nausea* & 8 & 11 & 10 & 30 & 29 & 30 \\
\hline Vomiting* & 5 & 7 & 6 & 17 & 17 & 17 \\
\hline Skin reaction ${ }^{*}$ & 2 & 6 & 4 & 7 & 15 & 12 \\
\hline Diarrhoea & 3 & 2 & 2 & 10 & 5 & 7 \\
\hline Indigestion & 5 & 6 & 5 & 17 & 16 & 16 \\
\hline Tremor & 2 & 1 & 1 & 7 & 3 & 4 \\
\hline
\end{tabular}

* Specified on questionnaires; other reactions volunteered.

advised to avoid as a result of an established medical disorder. 'Ethical-moral' included vegetarians, vegans and those who considered methods of producing veal and eggs as inhumane. In some instances more than one reason was given so that the numbers on the Tables are greater than the total of respondents.

The commonest physiological reason offered was nausea $-30 \%$ of those who suffered some physiological reaction and $10 \%$ of all respondents, (Table 2). Between 4 and $6 \%$ of all respondents $(12-17 \%$ of those who react) reported indigestion, vomiting, headachemigraine or skin reaction. Only a small number volunteered diarrhoea or tremor.

A total of sixty-seven foods was specified and they are grouped in Table 3; alcoholic beverages, vegetables, meat products, cheese and fish products being cited most frequently. Within the group reacting to dairy foods sixteen persons avoided cheese (six because of headache-migraine, six because of nausea); nine avoided butter or cream (three nausea, three indigestion) and four avoided milk (two nausea, two diarrhoea). Within the group 'sugar and sugar confectionery' most references were to chocolate, with seven reporting 
Table 3. Foods avoided because of adverse physiological reaction

\begin{tabular}{lccc}
\hline \hline & $\begin{array}{c}\text { No. of } \\
\text { subjects }\end{array}$ & $\begin{array}{c}\text { Percentage of } \\
\text { sufferers }\end{array}$ & $\begin{array}{c}\text { Percentage of } \\
\text { total } \\
\text { respondents }\end{array}$ \\
\hline Alcoholic beverages & 36 & 19.4 & 6.4 \\
Vegetables & 30 & 16.2 & 5.4 \\
Meat products & 29 & 15.6 & 5.2 \\
Cheese & 27 & 14.6 & 4.8 \\
Fish products & 23 & 12.4 & 4.1 \\
Other dairy products & 13 & 7.0 & 2.3 \\
Chocolate & 14 & 7.6 & 2.5 \\
Other sugar confisctionery & & & \\
and sugar & 8 & 4.3 & 1.4 \\
Cereals & 19 & 10.2 & 3.4 \\
Fats and oils & 10 & 5.4 & 1.8 \\
Fruit & 10 & 5.4 & 1.8 \\
Eggs & 5 & 2.7 & 0.9 \\
\hline \hline
\end{tabular}

headache-migraine, seven skin reactions, two nausea and one diarrhoea; seven avoided sugar itself because of an adverse reaction, while sixty-four avoided sugar and sugar confectionery for reasons of weight.

The major foods that cause reactions are meat fat twenty-one persons, meat eleven, cheese sixteen, chocolate sixteen, alcohol eighteen and red wine thirteen. Fewer than ten mentioned fried foods, butter-cream, shellfish, onions and caffeine. Occasional mention, namely between one and four, was made of oysters, cucumbers, mushrooms, kidneys, biscuits, bread, tapiona, nuts, liver, tomatoes, sweetbreads, brain, garlic, porridge, banana, peppers, cabbiage, asparagus, avocado, citrus fruit, strawberries, cheese cake, monosodium glutamate and tea.

A surprisingly small number, namely twenty-four persons, avoided alcohol for reasons other than physiological (although this included four who stated 'health' and two who stated 'medical'), compared with thirty-two who avoided it because of adverse reaction. This last figure subdivided into thirteen who avoided red wine (seven stated headachemigraine as the reason) and eighteen who mentioned alcohol (six stated headache-migraine as the reason, five gavie nausea) together with one who specified whiskey.

\section{Time of reaction}

Respondents were asked when the reaction took place and the replies were classed as 'immediate' if they ocsurred within $1 \mathrm{~h}$ of ingesting the food. $30 \%$ of all who reported a reaction stated that it was immediate, i.e. $10 \%$ of all respondents.

For seven out of the eight types of physiological reaction reported, 165 out of a total of 231 reactions were described as delayed; only for the eight persons reporting tremor did the same numbers report immediate and delayed reactions.

\section{Medical conditions}

There did not appear to be any relation between the existence of conditions usually associated with allergies such as hay fever, asthma and eczema, and avoidance of foods since those suffering these conditions were equally divided between groups reporting no avoidance, avoidance for physiological reasons and avoidance for other reasons. Of those who avoid foods for physiological reasons there were respectively 8,2 and $1 \%$ suffering from hay fever, asthma or eczema compared with 12,4 and $2 \%$ who do not avoid foods. 
Of the total reporting physiological symptoms only $6 \%$ of the males and $20 \%$ of the females, $14 \%$ overall, had taken medical advice.

\section{Non-physiological reasons for avoidance}

Of the groups of reasons for avoiding food listed, taste was mentioned 268 times, and texture 119 times. 'Weight' was volunteered by sixty-seven persons as the reason for avoiding cereals, sixty-four sugar confectionery, thirty-four milk products and thirty fats.

\section{DISCUSSION}

Within the limits of a survey of this type it can be concluded that approximately one third of the population suffers an adverse reaction to a food and that between 1 and $4 \%$ react to one of ten specific foods, together with a further three dietary substances, namely red wine, alcohol and caffeine. Smaller numbers react to other foods and a total of sixty-seven foods was specified by respondents. Frankland (1970) has stated that there is hardly a food described that has not caused an allergic reaction.

Our values may be an overestimate since those who suffer nausea because of taste or texture or for psychological reasons may have included themselves among those suffering physiological reactions. The high proportion, namely $71 \%$, reporting delayed reactions suggests that only a small proportion may be psychological. On the other hand, the values may be an underestimate since delayed reactions may not be attributed to food. It has been shown, for example, that relief from symptoms followed the elimination of various foods in cases where the patients were quite unaware of any food intolerance (Mackarness, 1976; Finn \& Cohen, 1978). Moreover, Vaz et al. (1978) noted that symptoms not usually ascribed to allergy such as lassitude, irritability and aching joints were produced by various foods and alleviated with cromoglycolate, again suggesting that our figures may be an underestimate.

There are few values in the literature to serve as a comparison. Bleumink (1970) quoted reports of 20 and $30 \%$; Rowe (1931) quoted 30\%. On the other hand, May \& Block (1978) administered foods in a double blind trial and found that only one third of those with a history of adverse reactions to foods could be confirmed; the difference may be due to psychological reactions (Garb \& Stunkard, 1974).

Saarinen \& Kajosaari (1980) reported that $3 \%$ of 330 children of 3 years of age were allergic to fish and 3\% to citrus fruits (allergy being defined as skin reaction or heavy vomiting after challenge). Among children with a family history (atopic disease in at least one parent or sibling) the incidence was $7 \%$ allergy towards fish and $13 \%$ towards citrus fruits.

The finding that eighty-six persons had not taken medical advice suggests that the frequency of adverse reactions to foods may be greater than medical records indicate. It is noteworthy that very few of those who suffered from hay fever, asthma and eczema stated that they avoided any food.

The situation is somewhat complicated since it is possible to affect reactivity of a food by processing. Frankland (1970) for example, reported allergic reactions to boiled egg but not to egg in cake, to orange but not to orange marmalade and pointed to the heat destruction of chlorogenic acid, an allergen identified in orange and also in coffee.

The 'worst' foods in the present investigation appear to affect about 5-6\% of the population questioned and this may possibly be regarded as a standard for comparison with novel foodstuffs. 


\section{REFERENCES}

Bleumink, E. (1970). Wld Rev. Nut. Diet. 12, 505.

Finn, R. \& Cohen, H. N. (1978). Lancet i, 426.

Frankland, A. W. (1970). S(C. Hlth J. 90, 243.

Garb, J. \& Stunkard, A. (1974). Am. J. Psychiat. 131, 1204.

Lancet (1979). Lancet i, 249.

Mackarness, R. (1976). Not all in the mind. London: Pan Books Ltd.

May, C. D. \& Block, S. A. (1978). Allergy 33, 166.

Monro, J., Bostoff, J., Garini, C. \& Zilkha, K. (1980). Lancet ii, 1.

Rowe, A. H. (1931). Food Ailergy; Its Manifestations, Diagnosis and Treatment. Philadelphia: Lea \& Febiger.

Saarinen, U. M. \& Kajosaari, M. (1980). Lancet i, 166.

Soothill, J. F. (1980). Lancet i, 166.

Vaz, G. A., Tan, L. K. T. \& Gerrard, J. W. (1978). Lancet i, 1066.

Wilson, J. A. (1979), Lancet i, 450. 